\title{
The infinitesimal, the deterministic, and the probabilistic: Alternate container inspection policies in invasive species management
}

\author{
Amitrajeet A. Batabyal · Dug Man Lee
}

Published online: 24 February 2007

(C) Springer Science+Business Media B.V. 2007

\section{Erratum to: Biol Invasions \\ DOI: 10.1007/s10530-006-0001-x}

This is to inform you that Mr. Dug Man Lee (email: konkuk56@kku.ac.kr) is the Correspond- ing author for the article titled "The Infinitesimal, the deterministic, and the probabilistic: Alternate container inspection policies in invasive species management", published in The Volume 8 Number 8 of Biological Invasions (pages 1663-1671).

The online version of the original article can be found at http://dx.doi.org/10.1007/s10530-006-0001-x

\footnotetext{
A. A. Batabyal

Department of Economics, Rochester Institute of Technology, 92 Lomb Memorial Drive, Rochester, NY 14623-5604, USA

D. M. Lee $(\square)$

Department of Economics, Konkuk University, \#322

Danwol-dong, Chungju, Chungbuk 380-701

South Korea

e-mail: konkuk56@kku.ac.kr
} 